\title{
EFEITOS DO SOMBREAMENTO NO DESEMPENHO DE EDIFICAÇÃO COM ENVELOPE ISOLADO NA ZB 2
}

\section{EFFECTS OF THE SHADING IN THE PERFORMANCE OF AN INSULATED ENVELOPE BUILDING IN THE ZB 2}

\author{
Sílvia Ruzicki Pereira ${ }^{1}$ \\ Universidade Federal de Pelotas, Pelotas, RS, Brasil, silvia-ruzicki@hotmail.com
}

Carolina de Mesquita Duarte ${ }^{2}$

Universidade Federal de Pelotas, Pelotas, RS, Brasil, carolinademesquitaduarte@hotmail.com

Eduardo Grala da Cunha ${ }^{3}$

Universidade Federal de Pelotas, Pelotas, RS, Brasil, eduardo.grala@ufpel.edu.br

Lisandra Fachinello Krebs ${ }^{4}$

Universidade Federal de Pelotas, Pelotas, RS, Brasil, liskrebs@gmail.com

Rodrigo Karini Leitzke ${ }^{5}$

Universidade Federal de Pelotas, Pelotas, RS, Brasil, rodrigokarinileitzke@gmail.com

Antonio César Silveira Baptista da Silva ${ }^{6}$

Universidade Federal de Pelotas, Pelotas, RS, Brasil, antoniocesar.sbs@gmail.com

Letiane Benincá7

Escola Politécnica, Faculdade Meridional, IMED, Passo Fundo, RS, Brasil, letiane.beninca@imed.edu.br

\section{Resumo}

Sabe-se que a altura dos edifícios da vizinhança, a relação dos espaçamentos entre as edificações e a largura das vias têm influência na absorção de radiação solar direta, no sombreamento das edificações e no consumo de energia nas edificações. Assim, este estudo tem por objetivo avaliar a influência do sombreamento do entorno em uma edificação unifamiliar com elevado isolamento térmico localizada na ZBB 2. O método utilizado nesse trabalho consiste na simulação computacional de edificação com diferentes configurações de entorno, dividindo-se em 5 etapas: definição da hipótese de pesquisa; simulação do nível de eficiência energética considerando o RTQ-R; modelagem do entorno e análise do rastreamento de sombras; simulação do desempenho energético e do nível de conforto térmico; e análise dos resultados. Foram modeladas oito diferentes possibilidades de sombreamento. A configuração que apresentou o menor consumo energético e maior nível de conforto térmico foi a edificação sombreada pelo entorno de 6 pavimentos, com consumo de climatização de $26,44 \mathrm{kWh} / \mathrm{m}^{2}$.ano e índice de conforto térmico de $97,72 \%$. Os resultados indicaram que o elevado nível de isolamento térmico de uma edificação gera um melhor desempenho termoenergético do envelope, mesmo com o sombreamento de paredes no período de inverno.

Palavras-chave: Sombreamento do entorno. Eficiência energética. Isolamento térmico. RTQ-R. Conforto térmico.

\begin{abstract}
It is known that the height of the buildings, the distance between the buildings and the width of the streets, have an influence on the solar radiation absorption and buildings shading and it also affects the consumption of the buildings. Furthermore, this study aims to evaluate the surrounds shading in a very insulated building, located in the Brazilian bioclimatic zone 2. The used method is characterized by computational simulation divided into five steps: definition of the research hypothesis; analysis of the energy efficiency level considering the RTQ-R regulation; surroundings modeling and shading tracking analysis; simulation of the energy performance of the building; simulation of the thermal performance of the building; and result from analysis. Eight different possibilities of the surround configurations were simulated. The model that presented the lower consumption was the building with 6 floors surroundings, with the consumption about $26,44 \mathrm{kWh} / \mathrm{m}^{2}$.year and with thermal comfort index about $97,72 \%$. Hence, it was possible to observe the building shading of an insulated building even during the winter period, since that does not influence the roof, it generates a better thermal energy performance of the envelope.
\end{abstract}

Keywords: Surround shading. Energy Efficiency. Thermal insulation. RTQ-R. Thermal Comfort

\section{How to cite this article:}

PEREIRA, Sílvia Ruzicki et al Efeitos do sombreamento no desempenho de edificação com envelope isolado na ZB 2. PARC Pesquisa em Arquitetura e Construção, Campinas, SP, v. 7, n. 3, p. 145-159, out. 2016. ISSN 1980-6809. Disponível em:

$<$ <ttp://periodicos.sbu.unicamp.br/ojs/index.php/parc/article/view/8647327>. Acesso em: 15 mar. 2017.

doi:http://dx.doi.org/10.20396/parc.v7i3.8647327.. 


\section{Introdução}

A população de diversos países busca meios alternativos de satisfazer suas necessidades energéticas minimizando o uso de recursos, empregando estratégias passivas de eficiência energética. A União Europeia, preocupada com esses aspectos, publicou a Diretiva 2010/31/UE, que estabelece as metas que os Estados-Membros devem alcançar e cumprir até 2020 para os novos edifícios, os quais deverão ser edifícios de consumo de energia quase zero (Nearly-Zero Energy Buildings - NZEB) (EPBD, 2010). Esses edifícios terão na sua gênese medidas de eficiência energética que, de forma passiva, reduzam as suas necessidades de consumo de energia relacionado ao seu uso e operação. Ou seja, o pressuposto básico de uma edificação NZEB é o elevado nível de eficiência energética.

Nesse contexto insere-se o conceito Passive House. Segundo Mcleod, Mead e Standen (2016) para atender todos os critérios da certificação Passive House deve-se implementar cinco princípios: bom nível de isolamento térmico do envelope, minimização de pontes térmicas, esquadrias de alto desempenho, ventilação com recuperação de calor e estanqueidade da edificação. O Passive House Institut exige que cinco critérios sejam cumpridos para que o projeto possa receber certificação Passive House: a) a demanda de energia para aquecimento não deve ser superior a $15 \mathrm{kWh} /\left(\mathrm{m}^{2}\right.$.a), ou a carga térmica não deve ser superior a $10 \mathrm{~W} / \mathrm{m}^{2}$; b) a demanda de energia para arrefecimento não deve ser superior a $15 \mathrm{kWh} /\left(\mathrm{m}^{2} . \mathrm{a}\right)$; c) a demanda de energia primária, energia total a ser usada para todas as aplicações domésticas (aquecimento, água quente e eletricidade doméstica) não deve exceder 120 $\mathrm{kWh} /\left(\mathrm{m}^{2} . \mathrm{a}\right)$; d) o edifício deve ser hermético, com um máximo de 0,60 renovações de ar por hora à pressão de 50 Pascal (ACH750); e) o conforto térmico deve ser atendido para todas as áreas de permanência durante o inverno, bem como no verão, não ultrapassando $10 \%$ das horas em um determinado ano à temperatura de $25^{\circ} \mathrm{C}$.

A Passive House, originalmente desenvolvida para países de clima frio, foi adaptada pela Passive-On para países de clima quente, na verdade menos frios em comparação à Alemanha, gênese da Passive House. A proposta de adaptação do Padrão Passive House (Passive-On) foi implementada com vistas inicialmente aos países localizados no sul da Europa, com um menor rigor climático no período frio. Portugal é um desses países e a experiência portuguesa foi também uma referência para o desenvolvimento deste trabalho.

Nos últimos anos, algumas iniciativas visando o aumento do desempenho termoenergético das edificações foram implementadas no Brasil, destacam-se assim, as normas de desempenho térmico de edificações NBR 15220 (ABNT, 2005) e NBR 15575 (ABNT, 2013), os regulamentos de eficiência energética RTQ-C (Requisitos Técnicos para a Qualidade do Nível de Eficiência Energética de Edificações Comerciais, Públicas e de Serviços) (INMETRO, 2013) e RTQ-R (Requisitos Técnicos para a Qualidade do Nível de Eficiência Energética de Edificações Residenciais) (INMETRO, 2012).

Dentro deste contexto insere-se este artigo, que tem por objetivo avaliar o impacto do sombreamento do entorno de uma edificação com elevado nível de isolamento térmico. Como indicadores de avaliação, são observados o nível de conforto térmico dos usuários de ambientes de permanência prolongada, quando analisado o edifício ventilado naturalmente, como também o consumo energético da edificação para o caso do edifício climatizado artificialmente.

\section{Fundamentação}

Uma das causas para o alto consumo de energia elétrica é a rápida densificação das cidades. Assis (2005) afirma que os estudos descritivos do clima urbano têm mostrado que, tanto em área tropical quanto temperada, a mudança climática local está associada a efeitos de transformação de energia na área urbana em função de sua morfologia, das propriedades térmicas dos materiais das superfícies e da produção de calor antropogênico, provocando a redução das taxas de resfriamento evaporativo e convectivo, em função da impermeabilização do solo, da diminuição da superfície coberta por vegetação e da redução da velocidade dos ventos pelo aumento da rugosidade superficial (ASSIS, 2005). Conforme Romero (2011), quanto maior for à densificação em um determinado local, menor será a incidência de radiação solar direta e maior o aumento de radiação difusa. Além disso, uma edificação pode ter diferentes comportamentos conforme o meio em que é inserida, pois segundo Mascaró (2009) o traçado urbano, as edificações, a arborização e outros pontos peculiares de um sítio podem modificar significativamente a intensidade e direção dos ventos registrados nas estações meteorológicas e o microclima do local.

Exemplificando a influência da arborização urbana para o microclima, um estudo publicado por Johansson et al. (2013) apresenta sua contribuição na redução da temperatura média radiante. A análise em microescala foi realizada para a cidade de São Paulo, através de simulações computacionais utilizando ENVI-Met v.3.1. Seis diferentes tecidos urbanos foram analisados para um dia típico de verão, no período das 11:00 h às 15:00 h, combinando a influência de vegetação e edifícios isolados. Johansson et al. (2013) concluíram que o sombreamento proporcionado pelas árvores em meio urbano contribui significativamente na redução da temperatura média radiante do entorno, sobretudo em áreas edificadas com 
pouca altura. Comparando-se o sombreamento gerado pelas árvores com o gerado pelos edifícios altos, é visto que nos locais onde foi proporcionado pelas árvores, a redução da temperatura média radiante foi maior que naqueles onde foi proporcionado pelos edifícios altos, independentemente do tipo de superfície do piso (grama ou asfalto). Assim como a relação dos espaçamentos entre as edificações, a altura dos edifícios do meio vizinho e a largura das vias tem influência na absorção, pelas edificações, de radiação solar direta e difusa quando emitida pelas superfícies dos edifícios ao redor e pelo solo.

Os estudos conduzidos por Soares (2015) e Oliveira (2013) caracterizaram que edificações residenciais com maior isolamento térmico no envelope apresentam para a zona bioclimática 2 melhor desempenho termoenergético. Pacheco (2013) realizou uma análise sobre o desempenho termoenergético de edificações situadas nas cidades de Belém - PA (clima quente) e Curitiba - PR (clima frio), com diferentes níveis de transmitância térmica, baixa absortância e de sombreamento que variam entre o nulo, parcial e completo. Pacheco (2013) observou que, para a cidade de Curitiba, uma edificação residencial com Nível 1 de transmitância térmica $\left(0,10 \mathrm{~W} / \mathrm{m}^{2} \mathrm{~K}, \quad 0,13 \mathrm{~W} / \mathrm{m}^{2} \mathrm{~K}\right.$, $0,11 \mathrm{~W} / \mathrm{m}^{2} \mathrm{~K}$ para cobertura, parede e piso respectivamente) em local de sombreamento nulo, possui o melhor desempenho térmico, com 2.016 graus-hora de desconforto térmico para calor e frio, enquanto que o nível $6\left(1,86 \mathrm{~W} / \mathrm{m}^{2} \mathrm{~K}, 3,47 \mathrm{~W} / \mathrm{m}^{2} \mathrm{~K}, 1,31 \mathrm{~W} / \mathrm{m}^{2} \mathrm{~K}\right.$ para cobertura, parede e piso respectivamente) apresentou 26.472 graushora localizada em local com sombreamento completo. Neste caso, observou-se que edifícios com menores transmitâncias térmicas de paredes, pisos e coberturas obtiveram um maior nível de conforto térmico quando sombreados totalmente.

Ainda sobre o estudo de Pacheco (2013), para a cidade de Belém, o nível de transmitância térmica da edificação que obteve melhor desempenho foi de Nível 1 e Nível 2 $\left(0,14 \mathrm{~W} / \mathrm{m}^{2} \mathrm{~K}, \quad 0,19 \mathrm{~W} / \mathrm{m}^{2} \mathrm{~K}, \quad 0,16 \mathrm{~W} / \mathrm{m}^{2} \mathrm{~K}\right.$ para cobertura, parede e piso respectivamente), com 8 graus-hora, situada em local com sombreamento completo, enquanto que a edificação com menor nível de conforto térmico foi a de transmitância térmica Nível $6\left(1,86 \mathrm{~W} / \mathrm{m}^{2} \mathrm{~K}, 3,47 \mathrm{~W} / \mathrm{m}^{2} \mathrm{~K}\right.$, $1,31 \mathrm{~W} / \mathrm{m}^{2} \mathrm{~K}$ para cobertura, parede e piso respectivamente), com 8.296 graus-hora, situada em local com sombreamento nulo. Em ambos os casos, o sombreamento e a menor transmitância térmica podem reduzir a temperatura radiante, que reduz a temperatura operativa e obtém maior conforto térmico.

Chvatal e Corvacho (2009) desenvolveram um estudo sobre a influência do aumento do isolamento térmico do envelope no desempenho termoenergético de edificações residenciais e comerciais localizadas em três cidades portuguesas. Também constataram que o aumento do isolamento térmico do envelope deve estar atrelado ao controle dos ganhos térmicos provenientes da radiação solar direta e dos ganhos internos de calor para evitar os problemas de sobreaquecimento.

Até o momento, as investigações sobre o efeito do sombreamento das fachadas priorizam os elementos integrantes do projeto com este fim (como os quebra-sóis). Há um número consideravelmente menor de estudos sobre a influência do entorno no desempenho termoenergético de edificações, tanto em etapas iniciais do projeto (como o caso de simulações computacionais), como em etapas de pós-ocupação, seja por meio de simulação ou por medições. A geometria do próprio projeto pode ocasionar sombras em suas fachadas, da mesma forma como o contexto onde o mesmo está inserido (por projeção das sombras de edificações vizinhas, por exemplo).

Orioli et al. (2012) caracterizam que em reabilitações de edificações as análises de eficiência energética geralmente levam em conta informações do edifício isolado, esquecendo-se da influência que o meio (construções e/ou vegetações adjacentes) possuem sobre a insolação ou não das fachadas. Os autores atribuem este fato a dificuldades em descrever-se detalhada e precisamente os objetos do entorno. Consequentemente, ter um bom conhecimento da geometria, localização e orientação solar é necessário para melhorar os cálculos e as predições das partes sombreadas e não sombreadas do edifício. Díaz-Vilariño et. al (2013) indicam que inserir os dados do entorno nas análises resultará em cálculos mais realistas, nos processos de retrofit energético. A mesma necessidade aplica-se também às novas edificações.

Nesse sentido observa-se que nem sempre o sombreamento provocado pelo entorno verticalizado poderá resultar em edificações com menores índices de conforto térmico e maiores consumos de energia. Dependendo do grau de isolamento térmico do envelope a influência do sombreamento poderá ser diferente. E é neste contexto que este trabalho se insere e pretende colaborar respondendo à seguinte problemática: 0 sombreamento excessivo do entorno prejudica o desempenho termoenergético de edificações com envelope isolado termicamente na Zona Bioclimática Brasileira 2?

\section{Método}

A realização deste trabalho consiste na análise quantitativa dos resultados obtidos através de simulação computacional. $\mathrm{O}$ método utilizado para sua realização divide-se em cinco etapas: definição da hipótese de pesquisa; simulação do nível de eficiência energética da edificação considerando o RTQ-R; modelagem do entorno e análise do rastreamento de sombras; simulação do 
desempenho energético da residência e do nível de conforto térmico dos usuários, e análise dos resultados. O infográfico caracterizado pela Figura 1 apresenta esquematicamente o método de pesquisa utilizado.

\section{ETAPA 1 - Definição da Hipótese de Pesquisa}

A hipótese a ser comprovada no trabalho pressupõe que o sombreamento excessivo do entorno em uma edificação com elevado nível de isolamento térmico localizado na Zona Bioclimática 2 pode maximizar o desempenho termoenergético da edificação.

\section{ETAPA 2 -Simulação do nível de eficiência energética da envoltória da edificação considerando o RTQ-R}

A segunda etapa consiste na avaliação do nível de eficiência energética da envoltória da edificação, para verão e inverno, conforme o RTQ-R. Para a apresentação da análise, caracteriza-se o projeto arquitetônico e a envoltória da edificação e, posteriormente, é feita a modelagem e configuração da edificação de acordo com os parâmetros do RTQ-R. As agendas de ocupação, iluminação, uso de equipamentos, ocupação, densidade de potência de iluminação, densidade de carga interna de equipamentos, como também a método para analisar a eficiência da envoltória da edificação, observaram o que preconiza o RTQ-R. Cabe-se ressaltar que a eficiência termoenergética do envelope com elevado isolamento térmico foi apresentada em Dalbem et al. (2017). No referido estudo o nível de eficiência energética da envoltória da edificação em questão foi analisado.

\section{Projeto arquitetônico}

De acordo com Köppen (PeeL, Finlayson, e Mcmahon, 2007) a classificação climática de Santa Maria/RS, apresenta clima temperado úmido com verão quente, possuindo estações bem definidas e inverno ameno, com chuvas distribuídas em todos os meses, não apresentando nenhuma estação seca, sendo úmido $\mathrm{o}$ ano todo (MORENO, 1961). A umidade relativa anual média é de $76,96 \%$ e a temperatura média anual é de $19,16^{\circ} \mathrm{C}$.

$\mathrm{O}$ projeto arquitetônico, elaborado anteriormente e publicado por Dalbem et al. (2015) foi desenvolvido de acordo com as estratégias passivas compiladas e baseadas no projeto da casa bioclimática de Pouey (2011), e atendendo às premissas do conceito Passive House. A edificação (Figuras 2 e 3 ) é uma residência unifamiliar de dois pavimentos com $126,45 \mathrm{~m}^{2}$, onde no térreo encontrase a cozinha e sala de estar integrados, solário, dois dormitórios, banheiro e garagem para um carro (ambiente não climatizado), e no pavimento superior, a área de trabalho, área técnica e lavabo.

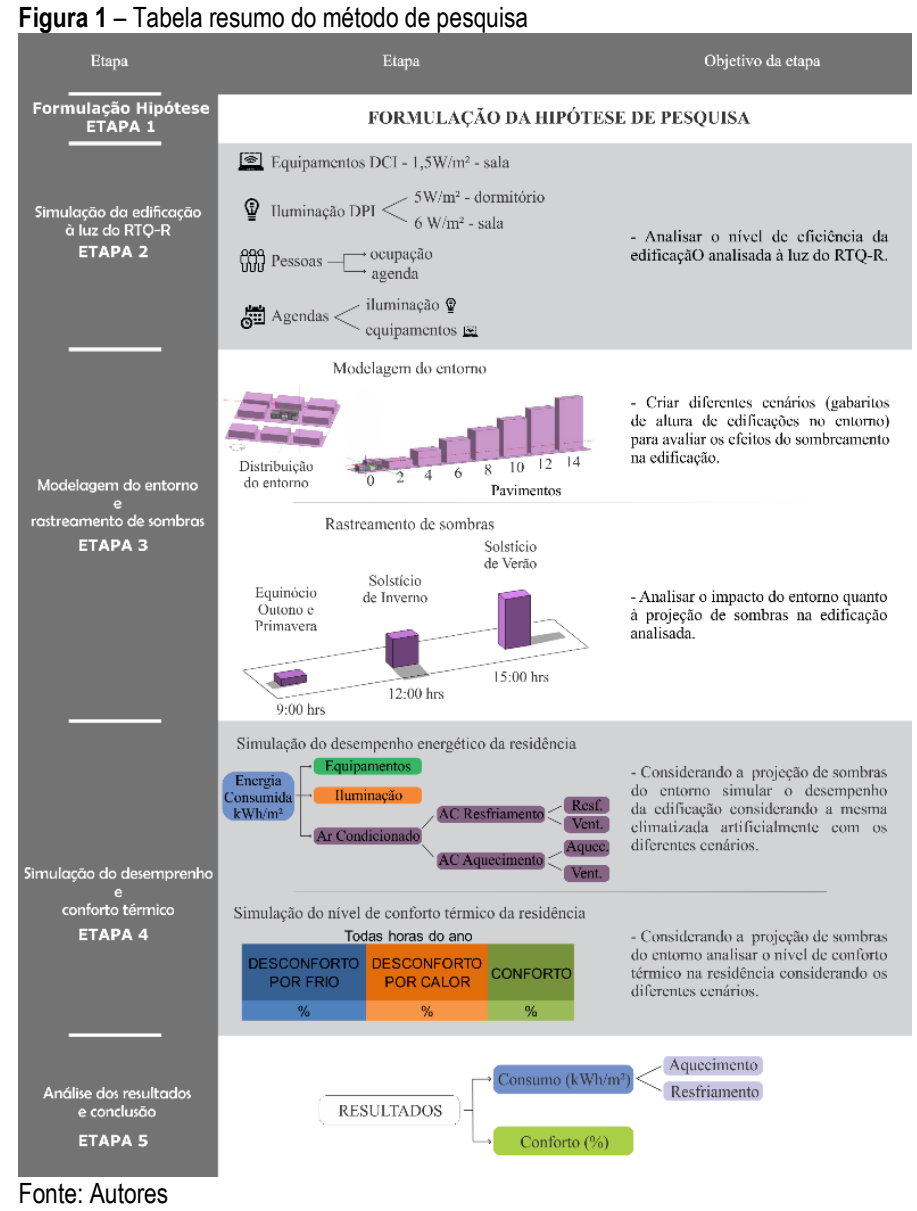

O projeto prioriza a maior fachada para o norte, aumentando os ganhos de radiação solar no período de inverno, e com as menores fachadas para leste e oeste reduzindo os ganhos indesejáveis no verão. Assim, o percentual de aberturas é maior na orientação norte, conforme a Tabela 1, onde localiza-se o solário com cobertura e paredes translúcidas, que conforme as demais esquadrias, possui elementos de proteção solar que permitem a entrada da radiação no inverno e bloqueiamna no verão.

\section{Características da envoltória da edificação}

Os elementos construtivos utilizados foram escolhidos para atender aos requisitos da Standard Passive House adaptadas pela Passive-On (PASSIVE-ON PROJECT, 2007), que recomenda para climas com estações climáticas bem definidas, com grande amplitude térmica ao longo do dia e mudanças bruscas de temperatura no decorrer do ano, oriundas do sul do continente europeu, a transmitância térmica próxima a $0,30\left[\mathrm{~W} /\left(\mathrm{m}^{2} \cdot \mathrm{K}\right)\right]$, para todos os elementos da envolvente opaca. As Tabelas 2, 3, 4 e 5 apresentam as principais propriedades da envoltória, entre elas a transmitância térmica total de cada elemento de construção, considerando as resistências superficiais interna e externa, conforme a NBR 15220 (ABNT, 2005). 


\begin{tabular}{|c|c|c|c|c|c|}
\hline & Total & Norte & Leste & Sul & Oeste \\
\hline $\begin{array}{l}\text { Área bruta de parede } \\
\left(\mathrm{m}^{2}\right)\end{array}$ & 219,95 & 68,64 & 32,98 & 85,35 & 32,98 \\
\hline $\begin{array}{l}\text { Área de abertura de } \\
\text { janelas }\left(m^{2}\right)\end{array}$ & 29,83 & 22,79 & 0,48 & 6,08 & 0,48 \\
\hline $\begin{array}{c}\text { Percentual de abertura - } \\
\text { esquadrias }(\%)\end{array}$ & 13,56 & 32,20 & 1,46 & 7,12 & 1,46 \\
\hline
\end{tabular}

\section{Características da envoltória da edificação}

Os elementos construtivos utilizados foram escolhidos para atender aos requisitos da Standard Passive House adaptadas pela Passive-On (PASSIVE-ON PROJECT, 2007), que recomenda para climas com estações climáticas bem definidas, com grande amplitude térmica ao longo do dia e mudanças bruscas de temperatura no decorrer do ano, oriundas do sul do continente europeu, a transmitância térmica próxima a $0,30\left[\mathrm{~W} /\left(\mathrm{m}^{2} \cdot \mathrm{K}\right)\right]$, para todos os elementos da envolvente opaca. As Tabelas 2, 3, 4 e 5 apresentam as principais propriedades da envoltória, entre elas a transmitância térmica total de cada elemento de construção, considerando as resistências superficiais interna e externa, conforme a NBR 15220 (ABNT, 2005).

\section{Configuração das simulações de acordo com os parâmetros do RTQ-R}

Para avaliar a eficiência da envoltória através das simulações no software DesignBuilder versão 3.2.0.073, a edificação foi configurada com o arquivo climático, BRASANTAMARIASWERA, referente à zona bioclimática brasileira 2 . A temperatura média do solo foi obtida através do programa Slab vinculado ao Energy Plus, conforme os valores médios das temperaturas internas e externas da edificação, e seguindo as determinações do RTQ-R (INMETRO, 2012).

As esquadrias utilizadas são de vidro duplo, compostas por três camadas, as externas de vidro com $3 \mathrm{~mm}$ de espessura cada, e com uma câmara de ar de $13 \mathrm{~mm}$ entre elas. $\mathrm{O}$ conjunto apresenta um fator solar (FS) de 0,69 e transmitância térmica (Uvidro) de 1,96 [W/( $\left.\left.\mathrm{m}^{2} . \mathrm{K}\right)\right]$. A caixilharia é de PVC com cor branca, com transmitância térmica $\left(\mathrm{U}_{\text {caixilharia }}\right)$ de $3,633\left[\mathrm{~W} /\left(\mathrm{m}^{2} . \mathrm{K}\right)\right]$. Tanto o projeto quanto as estratégias bioclimáticas utilizadas na concepção foram apresentados em Dalbem (2015).

Assim, segundo o RTQ-R, avalia-se apenas os ambientes de permanência prolongada, ou seja, os dois quartos, a sala de estar conjugada com a cozinha e o escritório (Tabela 6). $\mathrm{Na}$ Tabela 6 podemos observar além dos padrões de uso e ocupação preconizados no RTQ-R, as densidades de carga interna da sala de estar para equipamentos, e as densidades de potência de iluminação da sala de estar e dos dormitórios. Esses valores são definidos como condições de contorno preconizadas no RTQ-R. Os índices de ocupação foram apontados a partir de recomendações do RTQ-R, que contabiliza duas pessoas por dormitório, sendo a sala e o escritório ocupados por todos os usuários.

Figura 2 - Projeto arquitetônico, plantas baixas pavimentos térreo e superior
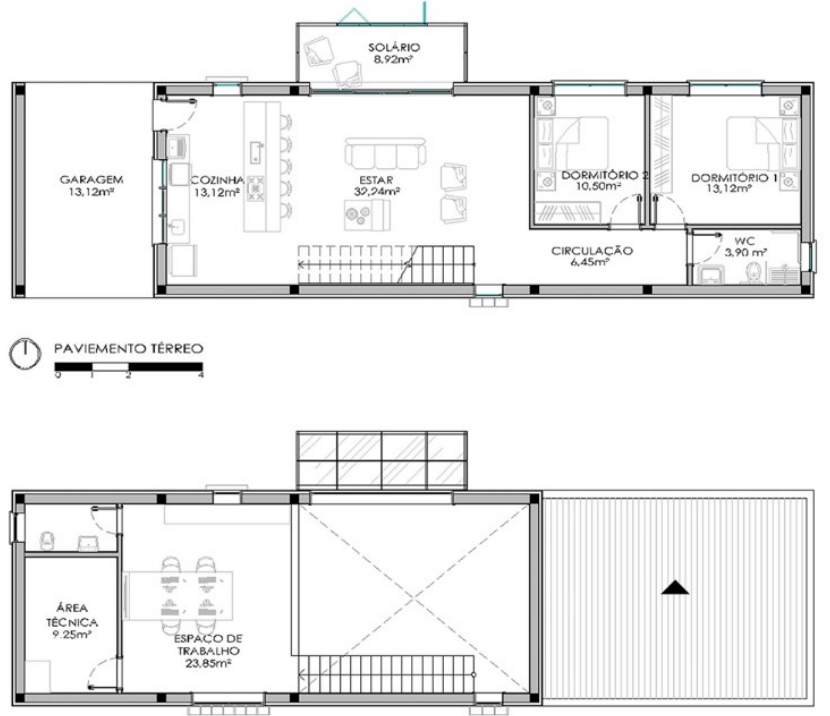

(1) PAVIMENTO SUPERIOR

Fonte: Dalbem et al. (2015)

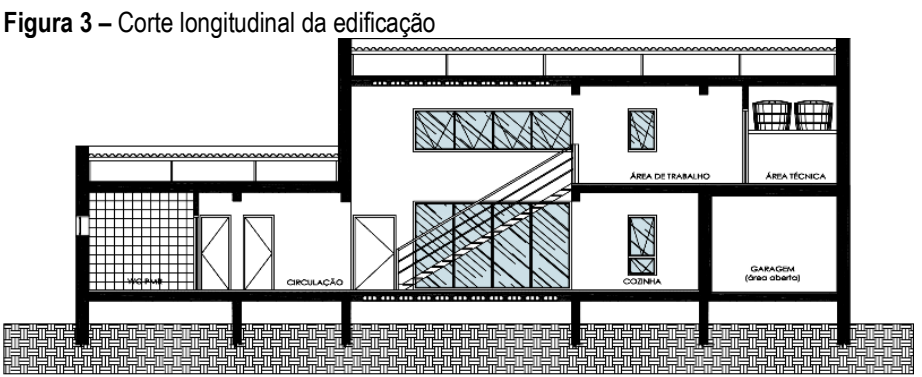

Corte Longitudinal AA'

Fonte: Dalbem et al. (2015)

O método de simulação termoenergética (INMETRO, 2012) avalia a eficiência energética da envoltória de unidades habitacionais autônomas (UH) e edificações unifamiliares. De acordo, com o RTQ-R, esse modelo foi dividido em naturalmente ventilado durante o período ocupado e condicionado artificialmente das 21:00 h às 8:00 h. O regulamento exige que essas duas situações sejam simuladas para avaliar o nível de desempenho da envoltória, para então fazer a comparação com os valores de referência das Tabelas de classificação dos níveis de eficiência energética da envoltória. Com a simulação da edificação naturalmente ventilada se obtém os indicadores de graus-hora de resfriamento para a temperatura operativa horária, que tem como temperatura base de cálculo $26^{\circ} \mathrm{C}$ e é avaliado nas 8.760 horas do ano para cada ambiente de permanência prolongada, de acordo com a equação 1 , caracterizando a avaliação do verão.

$G H_{R}=\sum\left(T_{0}-26^{\circ} \mathrm{C}\right)$

Equação 1 
Onde:

$G H_{R}$ : indicador de graus-hora para resfriamento;

$T_{0}$ : temperatura operativa horária $\left({ }^{\circ} \mathrm{C}\right)$.

Com os indicadores de graus-hora de resfriamento determinados, compara-se os valores com os níveis de eficiência da Tabela do arquivo climático utilizado (Tabela 7), que devem ser iguais ou menores que os níveis de eficiência. E com a simulação da edificação condicionada artificialmente, obtiveram-se os consumos relativos para aquecimento $\left(C_{A}\right)$, e para resfriamento $\left(C_{R}\right)$ dos ambientes de permanência prolongada da edificação, para que se possa determinar o equivalente numérico relativo para aquecimento (EqNumEnvAmb $b_{A}$ e para resfriamento (EqNumEnvAmb ${ }_{\text {Resfr }}$ ) de cada ambiente. Os consumos relativos devem ser iguais ou menores que os níveis de eficiência da Tabela 7.

Tabela 2 - Composição das paredes externas (ABNT, 2005)

\begin{tabular}{|c|c|c|c|c|c|c|}
\hline \multirow{6}{*}{ EXT. } & \multirow{6}{*}{ INT. } & \multicolumn{3}{|c|}{ PAREDES EXTERNAS } & Rsi= 0,13 & Rse $=0,04$ \\
\hline & & Constituição & e (m) & $\Lambda(\mathrm{W} /(\mathrm{mK}))$ & $\mathrm{R}\left(\mathrm{m}^{2} /(\mathrm{WK})\right)$ & $\mathrm{U}\left(\mathrm{W} /\left(\mathrm{m}^{2} \mathrm{~K}\right)\right)$ \\
\hline & & Reboco interno & 0,02 & 1,15 & 0,02 & \multirow{4}{*}{0,31} \\
\hline & & Tijolo Térmico Weber & 0,24 & 0,22 & 1,07 & \\
\hline & & Isolamento térmico - EPS & 0,08 & 0,04 & 2,00 & \\
\hline & & Reboco externo & 0,02 & 1,15 & 0,02 & \\
\hline
\end{tabular}

Legenda: $\mathrm{e}=$ espessura, $\lambda$ = condutividade térmica, $\mathrm{R}=$ resistência térmica, $\mathrm{U}=$ transmitância térmica. Fonte: Dalbem et al. (2015)

Tabela 3 - Composição das paredes externas - tratamento das pontes térmicas (ABNT, 2005)

\begin{tabular}{|c|c|c|c|c|c|c|}
\hline \multirow{6}{*}{ EXT. } & \multirow{4}{*}{$\begin{array}{l}\because \\
\therefore \\
\therefore\end{array}$} & \multicolumn{3}{|c|}{ PONTES TÉRMICAS } & \multirow{2}{*}{$\begin{array}{c}\text { Rsi= } 0,13 \\
R\left(m^{2} /(W K)\right)\end{array}$} & \multirow{2}{*}{$\begin{array}{c}\text { Rse }=0,04 \\
U\left(W /\left(m^{2} K\right)\right)\end{array}$} \\
\hline & & Constituição & e (m) & $\lambda(\mathrm{W} /(\mathrm{mK}))$ & & \\
\hline & & Reboco interno & 0,02 & 1,15 & 0,02 & \multirow{4}{*}{0,43} \\
\hline & & Pilar/Vigas de concreto & 0,24 & 1,75 & 0,14 & \\
\hline & \multirow{2}{*}{ INT. } & Isolamento térmico - EPS & 0,08 & 0,04 & 2,00 & \\
\hline & & Reboco externo & 0,02 & 1,15 & 0,02 & \\
\hline
\end{tabular}

Legenda: $\mathrm{e}=$ espessura, $\lambda$ = condutividade térmica, $\mathrm{R}=$ resistência térmica, $\mathrm{U}=$ transmitância térmica. Fonte: Dalbem et al. (2015)

Tabela 4 - Composição da laje de piso (ABNT, 2005)

\begin{tabular}{|c|c|c|c|c|c|}
\hline & \multicolumn{3}{|c|}{ LAJE DE PISO } & \multirow{2}{*}{$\begin{array}{c}\text { Rsi= } 0,17 \\
R\left(m^{2} /(W K)\right)\end{array}$} & \multirow{2}{*}{$\begin{array}{c}\text { Rse }=0,17 \\
\mathrm{U}\left(\mathrm{W} /\left(\mathrm{m}^{2} \mathrm{~K}\right)\right)\end{array}$} \\
\hline & Constituição & e (m) & $\lambda(\mathrm{W} /(\mathrm{mK}))$ & & \\
\hline \multirow{4}{*}{ 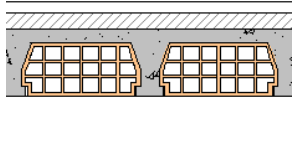 } & Revestimento cerâmico & 0,01 & 0,90 & 0,01 & \multirow{4}{*}{0,40} \\
\hline & Argamassa de assentam. & 0,04 & 1,15 & 0,02 & \\
\hline & Isolamento Térmico & 0,08 & 0,04 & 2,00 & \\
\hline & Laje pré-moldada & 0,25 & - & 0,19 & \\
\hline
\end{tabular}

Legenda: $\mathrm{e}=$ espessura, $\lambda$ = condutividade térmica, $\mathrm{R}=$ resistência térmica, $\mathrm{U}=$ transmitância térmica. Fonte: Dalbem et al. (2015)

Tabela 5 - Composição da cobertura (ABNT, 2005)

\begin{tabular}{|c|c|c|c|c|c|}
\hline & \multicolumn{3}{|c|}{ COBERTURA } & Rsi $=0,10$ & Rse $=0,04$ \\
\hline & Constituição & e (m) & $\lambda(\mathrm{W} /(\mathrm{mK}))$ & $\mathrm{R}\left(\mathrm{m}^{2} /(\mathrm{WK})\right)$ & $\mathrm{U}\left(\mathrm{W} /\left(\mathrm{m}^{2} \mathrm{~K}\right)\right)$ \\
\hline AR & Reboco interno & 0,02 & 1,15 & 0,02 & \multirow{4}{*}{0,41} \\
\hline \multirow{3}{*}{ 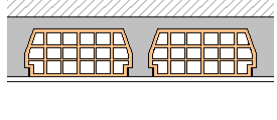 } & Laje pré-moldada & 0,25 & - & 0,19 & \\
\hline & Isolamento térmico - EPS & 0,08 & 0,04 & 2,00 & \\
\hline & Reboco externo & 0,02 & 1,15 & 0,02 & \\
\hline
\end{tabular}

Legenda: $\mathrm{e}=$ espessura, $\lambda$ = condutividade térmica, $\mathrm{R}=$ resistência térmica, $\mathrm{U}=$ transmitância térmica. Fonte: Dalbem et al. (2015)

Tabela 6 - Parâmetros utilizados na simulação

\begin{tabular}{|c|c|c|c|c|}
\hline Parâmetros & \multicolumn{4}{|c|}{ Valores Adotados } \\
\hline \multirow{2}{*}{$\begin{array}{c}\text { Padrão de uso - } \text { Ocupação } \\
\left(\text { pessoa } / \mathrm{m}^{2}\right)\end{array}$} & Dormitório 1 & Dormitório2 & Sala de Estar / Cozinha & Escritório \\
\hline & 0,13 & 0,18 & 0,07 & 0,07 \\
\hline \multirow{2}{*}{ Padrão de uso - $\quad$ lluminação $\left(\mathrm{W} / \mathrm{m}^{2}\right)$} & Dormitório 1 & Dormitório2 & Sala de Estar / Cozinha & Escritório \\
\hline & 5 & 5 & 6 & 6 \\
\hline \multirow{2}{*}{ Padrão de uso - Equipamentos $\left(\mathrm{W} / \mathrm{m}^{2}\right)$} & Dormitório 1 & Dormitório2 & Sala de Estar / Cozinha & Escritório \\
\hline & Desligado & Desligado & 2,00 & 2,00 \\
\hline Setpoint de aquecimento $\left({ }^{\circ} \mathrm{C}\right)$ & \multicolumn{4}{|c|}{$22^{\circ}$} \\
\hline Setpoint de resfriamento $\left({ }^{\circ} \mathrm{C}\right)$ & \multicolumn{4}{|c|}{$24^{\circ}$} \\
\hline \multirow{2}{*}{$\begin{array}{l}\text { Coeficiente de Performance do sistema de } \\
\text { condicionamento de ar - COP (W/W) }\end{array}$} & \multicolumn{2}{|c|}{ Aquecimento } & \multicolumn{2}{|c|}{ Resfriamento } \\
\hline & \multicolumn{2}{|c|}{2,75} & \multicolumn{2}{|c|}{3,00} \\
\hline
\end{tabular}

Fonte: adaptado do RTQ-R, INMETRO (2012) 
Tabela 7 - Valores de referência para classificação do nível da eficiência energética da envoltória pelo método de simulação para a ZB2

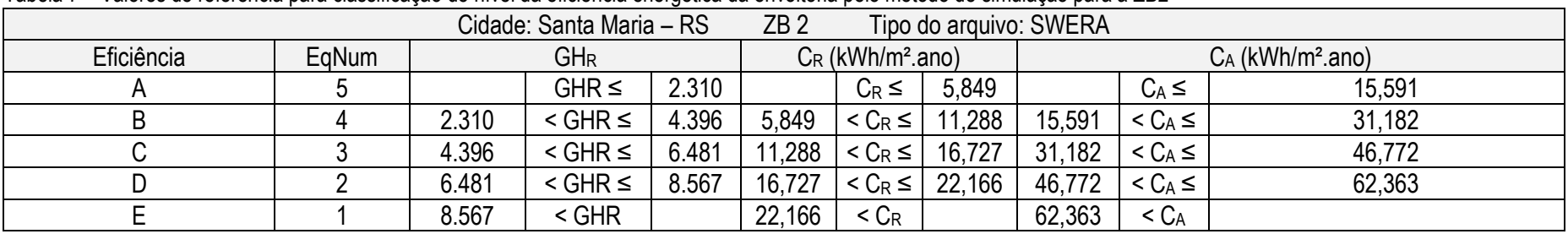

Fonte: INMETRO (2012)

Através da ponderação dos EqNumEnvAmb $b_{\text {Resfr }}$ pelas áreas úteis dos ambientes avaliados $\left(A U_{a m b}\right)$ é possível obter o equivalente numérico da envoltória da UH para resfriamento (EqNumEnv ${ }_{\text {Resfr }}$ ). E o mesmo se faz com o $E q N u m E n v A m b_{A}$ para obter o equivalente numérico da envoltória da UH para aquecimento $\left(E^{2 N u m E n v_{A}}\right)$.

Para a zona bioclimática 2, o equivalente numérico da envoltória da unidade habitacional autônoma é obtido por meio da Equação 2.

EqNumEnv $=0,44 x$ EqNumEnv $_{\text {Resfr }}+0,56 x$ EqNumEnv $_{A}$ Equação 2 - Fonte: INMETRO (2012)

Onde:

EqNumEnv: equivalente numérico da envoltória da $\mathrm{UH}$; EqNumEnv Resfr $_{\text {: }}$ equivalente numérico da envoltória da UH para resfriamento;

EqNumEnv ${ }_{A}$ : equivalente numérico da envoltória da $\mathrm{UH}$ para aquecimento.

Com a pontuação final obtida a partir da equação do EqNumEnv determina-se a classificação do nível de eficiência da envoltória da edificação, que varia de A (mais eficiente) a $\mathrm{E}$ (menos eficiente).

\section{ETAPA 3 - Modelagem do entorno e análise do rastreamento de sombras}

\section{Modelagem do entorno}

A ocupação dos terrenos do entorno foi baseada nas diretrizes gerais do Plano Diretor de Pelotas (Lei no 1672), em relação aos recuos e largura das vias para a Zona Residencial 1. Assim, conforme o plano diretor, usou-se 4 metros de recuo de ajardinamento, 2,5 $\mathrm{m}$ de recuos laterais, 3,5 $\mathrm{m}$ de recuo de fundos e $16 \mathrm{~m}$ de largura da via. Para os edifícios do entorno foram definidos oito volumetrias diferentes, sem entorno construído, e com 2 , $4,6,8,10,12$ e 14 pavimentos, sendo que cada pavimento contabiliza $3 \mathrm{~m}$. Os edifícios periféricos possuem comprimento de $21,84 \mathrm{~m}$, e profundidade de $13,37 \mathrm{~m}$, nas configurações de até 8 pavimentos, e diminuindo $2 \mathrm{~m}$ a cada configuração seguinte, já que segundo o plano diretor, acima de $24 \mathrm{~m}$ o recuo de ajardinamento aumenta $1 \mathrm{~m}$ para cada pavimento que ultrapassa a altura caracterizada. A Figura 4 ilustra o entorno com 2 pavimentos e a Figura 5 o entorno com 14 pavimentos.

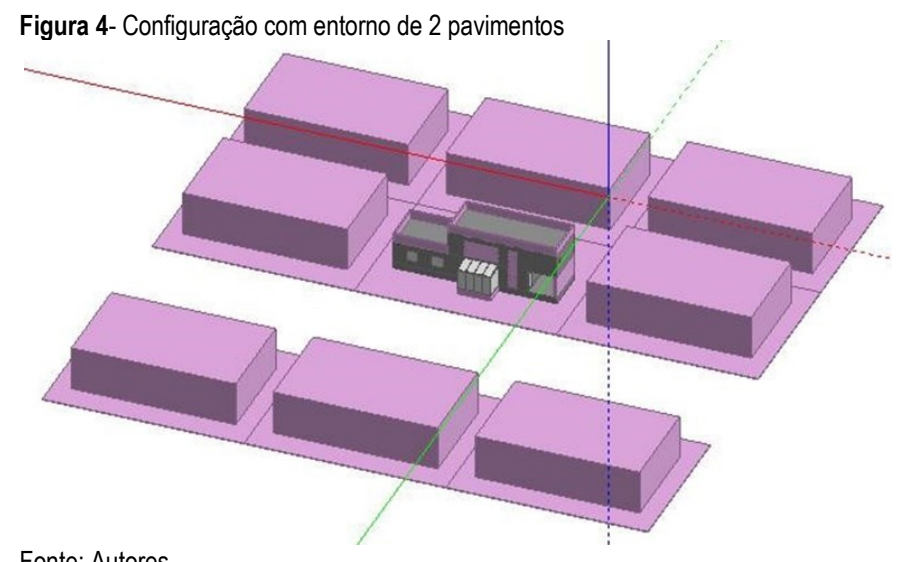

Fonte: Autores

Figura 5- Configuração com entorno de 14 pavimentos

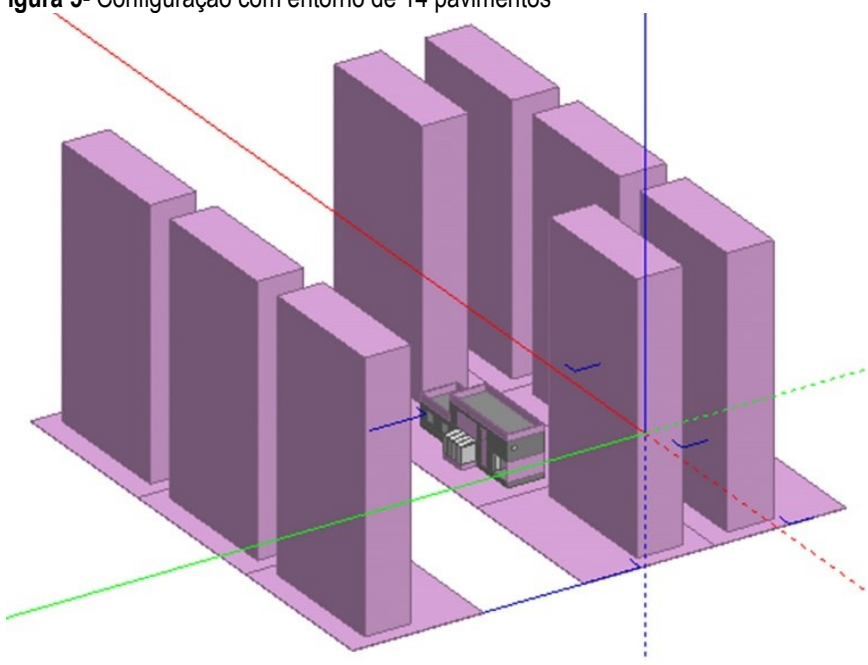

Fonte: Autores

\section{Rastreamento de sombras}

Para analisar a influência do entorno na edificação em relação à projeção de sombras, foi realizada uma análise do rastreamento de sombras no equinócio e nos solstícios de verão e inverno, nas seguintes horas: 09h00min, $12 \mathrm{~h} 00 \mathrm{~min}$ e às $15 \mathrm{~h} 00 \mathrm{~min}$. . Evidenciando a incidência de sombra sobre a edificação em análise, partindo da sombra própria sem entorno físico, posteriormente com entorno de edificações de 2, 4, 6, 8, 10, 12 e 14 pavimentos. Assim, foi possível analisar a interferência das edificações vizinhas no sombreamento de paredes e cobertura da 
edificação em análise. Por intermédio do Rastreamento de sombras foi possível observar, por exemplo, que no caso da edificação sombreada por entorno com 6 pavimentos, a situação de menor consumo de climatização e maior conforto térmico, tivemos o sombreamento das paredes no período de inverno, mas não o da cobertura.

\section{Simulação do desempenho energético da residência}

$\mathrm{Na}$ configuração ventilado naturalmente para o período das $09 \mathrm{~h} 00 \mathrm{~min}$ às $20 \mathrm{~h} 59 \mathrm{~min}$ e climatizado artificialmente das $21 \mathrm{~h} 00 \mathrm{~min}$ às $08 \mathrm{~h} 59 \mathrm{~min}$, os parâmetros configurados correspondem ao RTQ-R, de acordo com a Tabela 6 apresentada anteriormente, e com temperatura de termostato de $20^{\circ} \mathrm{C}$. Com a simulação, foi possível determinar a energia consumida na edificação, com a soma dos valores de consumo de equipamentos e iluminação, e do consumo de ar condicionado (aquecimento + resfriamento) obtidos nas simulações em $\mathrm{kWh} / \mathrm{m}^{2}$ ano. A simulação possibilitou avaliar e comparar o consumo energético da residência nas oito diferentes alturas do entorno.

\section{ETAPA 4 - Simulação do desempenho térmico e do nível de conforto térmico da residência}

A configuração ventilada naturalmente 24 horas foi estabelecida de acordo com os parâmetros do RTQ-R quanto à ocupação, carga interna de equipamentos e densidade de potência de iluminação. Por outro lado, como o objetivo foi o de avaliar o nível de conforto térmico dos ambientes interiores de permanência prolongada, a temperatura de termostato foi ajustada para $25^{\circ} \mathrm{C}$. Na análise do nível de conforto térmico, conforme Martins (2009), o setpoint de temperatura para a abertura de janelas para ventilação natural mais adequado para a Zona Bioclimática 2 é $25^{\circ} \mathrm{C}$. $\mathrm{O}$ valor de referência sugerido no RTQ-R para o cálculo de graus-hora para a análise do desempenho da envoltória é $20^{\circ} \mathrm{C}$. Este valor, quando definido como temperatura para abertura das janelas, gera desconforto térmico por frio. Como na análise do nível de conforto térmico dos usuários de ambientes de permanência prolongada o objetivo não é avaliar a envoltória da edificação com base no número de graushora, mas sim o nível de conforto térmico, baseado no índice do conforto adaptativo da ASHRAE 55 (2010), a temperatura de $25^{\circ} \mathrm{C}$ foi utilizada como setpoint de abertura das janelas. A partir dos dados de saída de temperatura operativa interna e temperaturas externas, obtidos nas simulações, foram calculadas as médias horárias mensais. A partir da equação 3 e com a temperatura média mensal externa obtida foi possível calcular a temperatura operativa de conforto mês a mês.

$$
\mathrm{T}_{\mathrm{oc}}=18,9+0,255 \mathrm{~T}_{\mathrm{ext}} \quad \text { Equação } 3
$$

$\mathrm{T}_{\mathrm{oc}}=$ Temperatura operativa de conforto;

$\mathrm{T}_{\mathrm{ext}}=$ Temperatura média mensal externa.

Fonte: ASHRAE 55 (2010)

Com as temperaturas operativas de conforto de todos os meses calculadas, considerando o limite de conforto para $80 \%$ de aceitabilidade, foi possível obter as horas de conforto térmico e as horas de desconforto por frio, considerando os valores abaixo do limite de aceitabilidade e o desconforto por calor acima do limite. Com essa metodologia foi possível obter as horas de conforto térmico do ambiente e comparar os 8 diferentes casos do entorno, para avaliar qual seria o nível de sombreamento mais adequado para o edifício com elevado nível de isolamento térmico do envelope na zona bioclimática brasileira 2.

\section{ETAPA 5 - Análise dos resultados}

Através das simulações realizadas no software DesignBuilder, pode-se avaliar e comparar o desempenho da edificação nas três configurações base, com condições de ventilação diferentes para as oito possibilidades de sombreamento modeladas. Com a simulação do modelo configurado para as condições de ventilação segundo o RTQ-R foi possível determinar o nível de eficiência da envoltória. Já com a configuração climatizada artificialmente as 24 horas obteve-se o valor de consumo energético da residência em kWh.ano, e na simulação do modelo ventilado naturalmente 24 horas chegou-se ao nível de conforto térmico adaptativo da edificação. Para a análise desses resultados serão apresentados infográficos resumindo os valores obtidos nas simulações para auxiliar sua compreensão. Cabe ressaltar que, em consonância com os resultados de Pacheco (2013), a situação de melhor desempenho termoenergético da edificação foi quando a residência esteve com as paredes totalmente sombreadas pela configuração de entorno com 6 pavimentos de altura. Quando a edificação esteve com a cobertura também sombreada os resultados apontaram a necessidade de maior consumo para aquecimento dos ambientes de permanência prolongada. E é nesta lacuna que este trabalho se inseriu. Os resultados das simulações permitiram analisar além do sombreamento das paredes a influência também do sombreamento da cobertura da edificação com elevado nível de isolamento térmico no desempenho termoenergético.

\section{Análise dos resultados RTQ-R}

A simulação com parâmetros do RTQ-R para uma edificação super-isolada foi realizada para definir o nível de eficiência da residência estudada, e como resultado, já apresentado anteriormente, obteve-se nível A para todos os compartimentos de permanência prolongada, 
classificando a edificação como nível A, como mostra a Figura 9.

\section{Rastreamento}

Para melhor compreender esses resultados, fez-se um estudo sobre o rastreamento de sombras gerado por cada entorno da residência em análise, como mostram a Figura 6, Figura 7 e Figura 8.

Assim foi possível perceber que no inverno a edificação recebe radiação solar direta de forma parcial para o entorno de 4 e 6 pavimentos com sombreamento apenas nas fachadas e parte da cobertura e, apresenta-se totalmente sombreada nos casos com 8, 10, 12 e 14 pavimentos no entorno. Enquanto isso, para as 12 horas, o rastreamento apresentou semelhança, apenas com a diferença para o entorno com 8 pavimentos, parcialmente sombreado. Já nos resultados para as 15 horas, a edificação obteve o mesmo resultado das 9 horas. Durante o outono e primavera, a edificação para as 9 horas, foi sombreada parcialmente para os entornos com 4, 6, 8 e 10 pavimentos, apresentando interferência no ganho de energia solar da residência apenas em parte da cobertura, enquanto que os demais obtiveram sombreamento nulo, igualmente para os casos representados pelas 12 horas. Para o verão, o rastreamento apontou para as 9 horas sombreamento parcial em todos os casos, exceto o sem entorno, em que os edifícios ao redor não exercem influência no ganho de energia solar da residência. Para as 12 horas, todos os casos obtiveram sombreamento nulo e para as 15 horas apenas a situação sem entorno obteve este resultado, pois os demais obtiveram sombreamento parcial, com parte das fachadas e coberturas sombreadas.

\section{Edifício condicionado artificialmente 24 horas}

Conforme as simulações de todos os casos de sombreamentos gerados pelo entorno sobre a edificação em evidência com uso de condicionamento de ar 24 horas por dia, percebeu-se, conforme a Figura 9 e Figura 10, que o maior consumo de energia elétrica foi na configuração sem entorno com $31,69 \mathrm{kWh} / \mathrm{m}^{2}$.ano e com entorno de edifícios com 2 pavimentos de altura, com 30,79 $\mathrm{kWh} / \mathrm{m}^{2}$.ano, ambos com $94 \%$ da energia consumida no condicionamento artificial para resfriar o ambiente interno. Enquanto que as configurações que apresentaram menor consumo energético foram as com entorno de 6 pavimentos, com $26,44 \mathrm{kWh} / \mathrm{m}^{2}$.ano, e com entorno de 8 pavimentos, com $26,92 \mathrm{kWh} / \mathrm{m}^{2}$.ano, apresentando $90 \%$ e $81 \%$ de energia consumida no condicionamento artificial para resfriar o ambiente, respectivamente. Isso ocorre, pois na configuração sem entorno, a residência recebe radiação solar direta sobre as paredes e cobertura em todas as épocas do ano, conforme ilustrado no infográfico sobre o rastreamento de sombras. Assim, como a edificação possui envoltória com elevado nível de isolamento térmico, com transmitância térmica de $0.31 \mathrm{~W} /\left(\mathrm{m}^{2} \mathrm{k}\right)$ para parede e transmitância de $0.41 \mathrm{~W} /\left(\mathrm{m}^{2} \mathrm{k}\right)$ para cobertura, o fluxo de calor é reduzido e acaba por dificultar a perda de calor no interior da edificação, causando um superaquecimento no ambiente e o aumento do uso de ar condicionado para o resfriamento, obtendo o mesmo resultado para a configuração de entorno com 2 pavimentos.

Já o exemplar que apresentou menor consumo energético, com entorno de 6 pavimentos, apresentou resultado muito próximo ao com entorno de 8 pavimentos, com diferencial do primeiro apresentar na cobertura, componente mais exposto à influência do elemento climático radiação solar durante todo o ano, enquanto que a segunda não. Além disso, analisando os gráficos dos fluxos térmicos, conforme Figura 11 e Figura 12, das configurações com entorno de 4 e 8 pavimentos, a fim de melhor compreender os resultados para o período do inverno, percebeu-se que os três recebem grande parte do calor por radiação solar direta através das esquadrias dos dormitórios, com orientação solar Norte. No período das $9 \mathrm{~h}$ às $16 \mathrm{~h}$, também se verificou que a perda de calor ocorre por meio das superfícies opacas da sala de estar. Assim, a configuração com entorno de 4 pavimentos apresentou o maior ganho de energia solar pelas esquadrias, pois a presença de radiação solar nas superfícies transparentes, levam ao aumento do calor no interior da edificação e consequentemente ao aumento do consumo de energia elétrica, uma vez que o calor recebido só pode ser eliminado através da climatização artificial, que mantém a temperatura interna menor que a externa. Sendo assim, a energia consumida pela configuração com entorno de 4 pavimentos foi de $2,3 \%$ maior do que a configuração com entorno de 8 pavimentos. Quanto à perda de calor, grande parte ocorreu pelas paredes da sala de estar, no período das $8 \mathrm{~h}$ às $22 \mathrm{~h}$ com picos às $12 \mathrm{~h}$ e às $20 \mathrm{~h}$ na configuração com entorno de 4 pavimentos, apresentando um consumo maior de $1,03 \%$ do que a configuração com entorno de 8 pavimentos. Isso ocorreu, porque a configuração menos eficiente, recebe radiação solar direta às $12 \mathrm{~h}$ fazendo com que o consumo de energia de condicionamento de ar para resfriar, retirando o calor do ambiente interno para o externo, seja maior do que as configurações com entorno de 6 e 8 pavimentos, em que a face Norte apresenta-se sombreada nesse período do dia.

No verão, conforme Figura 12, os índices são maiores, pois a configuração com entorno de 4 pavimentos recebeu $5,5 \%$ mais calor através da radiação solar por intermédio das esquadrias dos dormitórios do que a configuração com entorno de 8 pavimentos, consumindo mais energia com uso de condicionamento de ar para resfriar o ambiente interno, já que nesta configuração as paredes aparecem sombreadas. Com relação à perda de calor, também pelas superfícies opacas da sala de estar, por apresentar sombreamento parcial, observa-se que a configuração com 
PEREIRA, Sílvia Ruzicki et al.

Efeitos do sombreamento no desempenho de edificação com envelope isolado na ZB 2

Figura 6- Rastreamento solar nos equinócios de outono e primavera. EQUINOCIO OUTONO E PRIMAVERA (21/03 e 21/09)

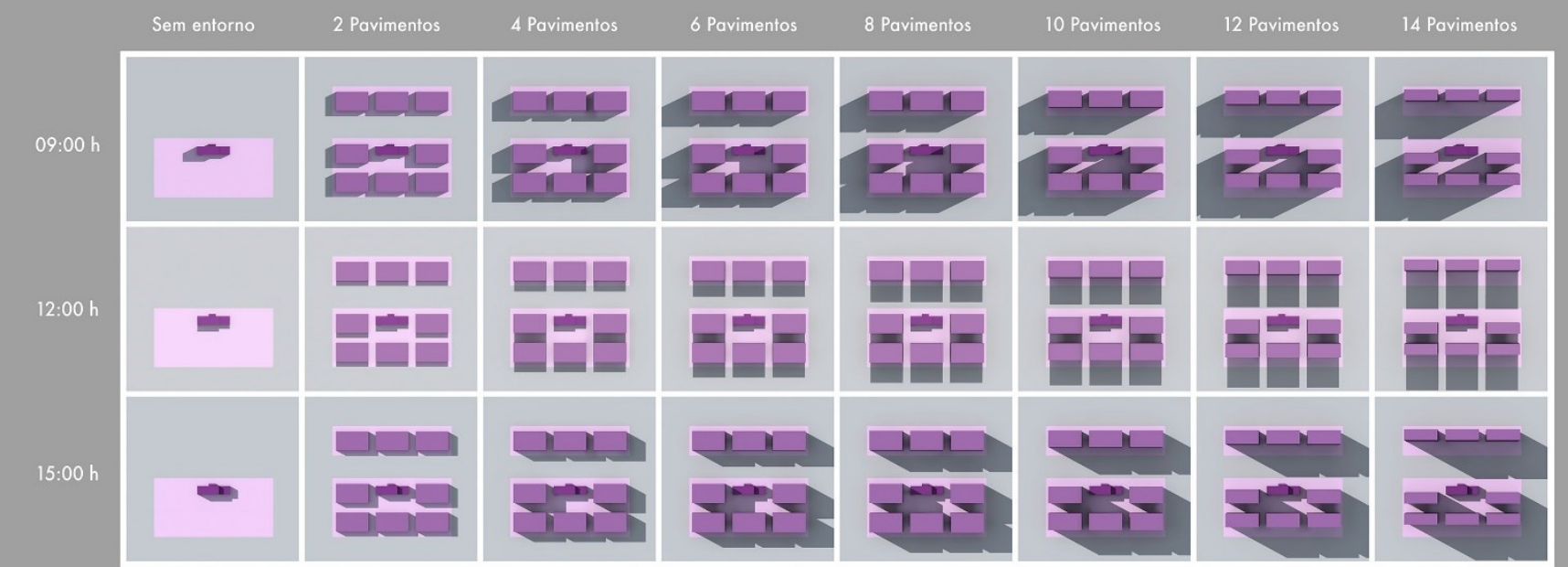

Fonte: Autores

Figura 7- Rastreamento solar no solstício de inverno. SOLSTICIO INVERNO $(21 / 06)$

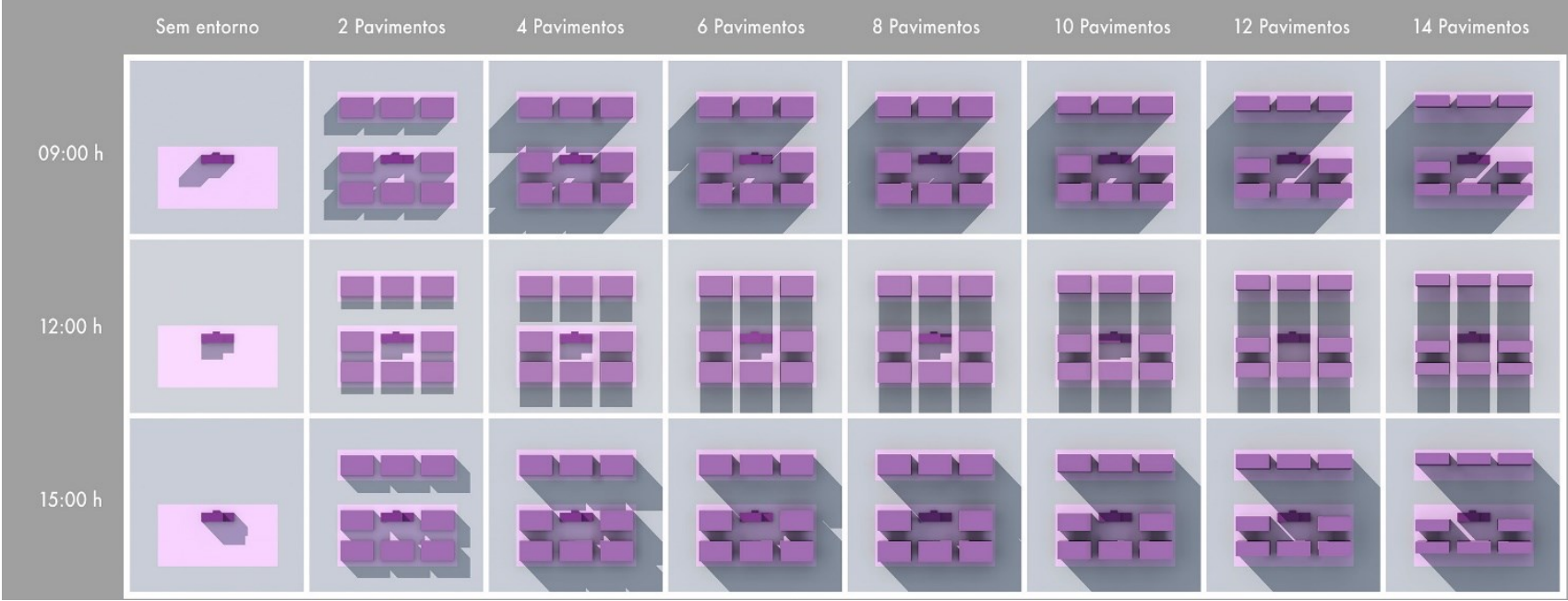

Fonte: Autores

Figura 8 - Rastreamento solar no solstício de verão

\begin{tabular}{|c|c|c|c|c|c|c|c|c|}
\hline & \multicolumn{8}{|c|}{ SOLSTICIO VERÃO $(21 / 12)$} \\
\hline & Sem entorno & 2 Pavimentos & 4 Pavimentos & 6 Pavimentos & 8 Pavimentos & 10 Pavimentos & 12 Pavimentos & 14 Pavimentos \\
\hline \multirow{3}{*}{$09: 00 \mathrm{~h}$} & & D. $\|$ & I 1 & II & | I I & 111 & II & man \\
\hline & $=$ & 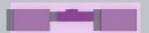 & $-x$ & $-2=$ & $1=$ & th & $=$ & $=$ \\
\hline & & 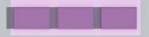 & 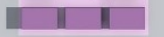 & 11 & 11 & $\|$ & | & 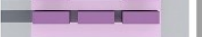 \\
\hline \multirow[b]{2}{*}{ 12:00 h } & & $\square \square \square$ & $\square \square \square$ & $\square \square \square$ & $\square \square \square$ & $\square \square \square$ & $\square \square \square$ & $\square=\square$ \\
\hline & $=$ & $\square=\square$ & $\square=\square$ & $\square=\square$ & at & 므는 & $a^{0}$ & -5 \\
\hline \multirow{3}{*}{$15: 00 \mathrm{~h}$} & & 11 & 111 & 11 & 11 & 11 & $1 /$ & 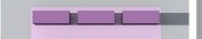 \\
\hline & $=$ & $1=$ & 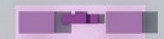 & 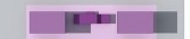 & $t=$ & ar & $1=$ & -1 \\
\hline & & 11 & 111 & 111 & 11 & 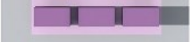 & III & 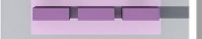 \\
\hline
\end{tabular}


PEREIRA, Sílvia Ruzicki et al.

Efeitos do sombreamento no desempenho de edificação com envelope isolado na ZB 2

Figura 9 - Classificação do nível de eficiência da edificação a partir do RTQ-R

MÉTODO DE SOMBREAMENTO POR PRÉDIOS NO ENTORNO RTQ-R

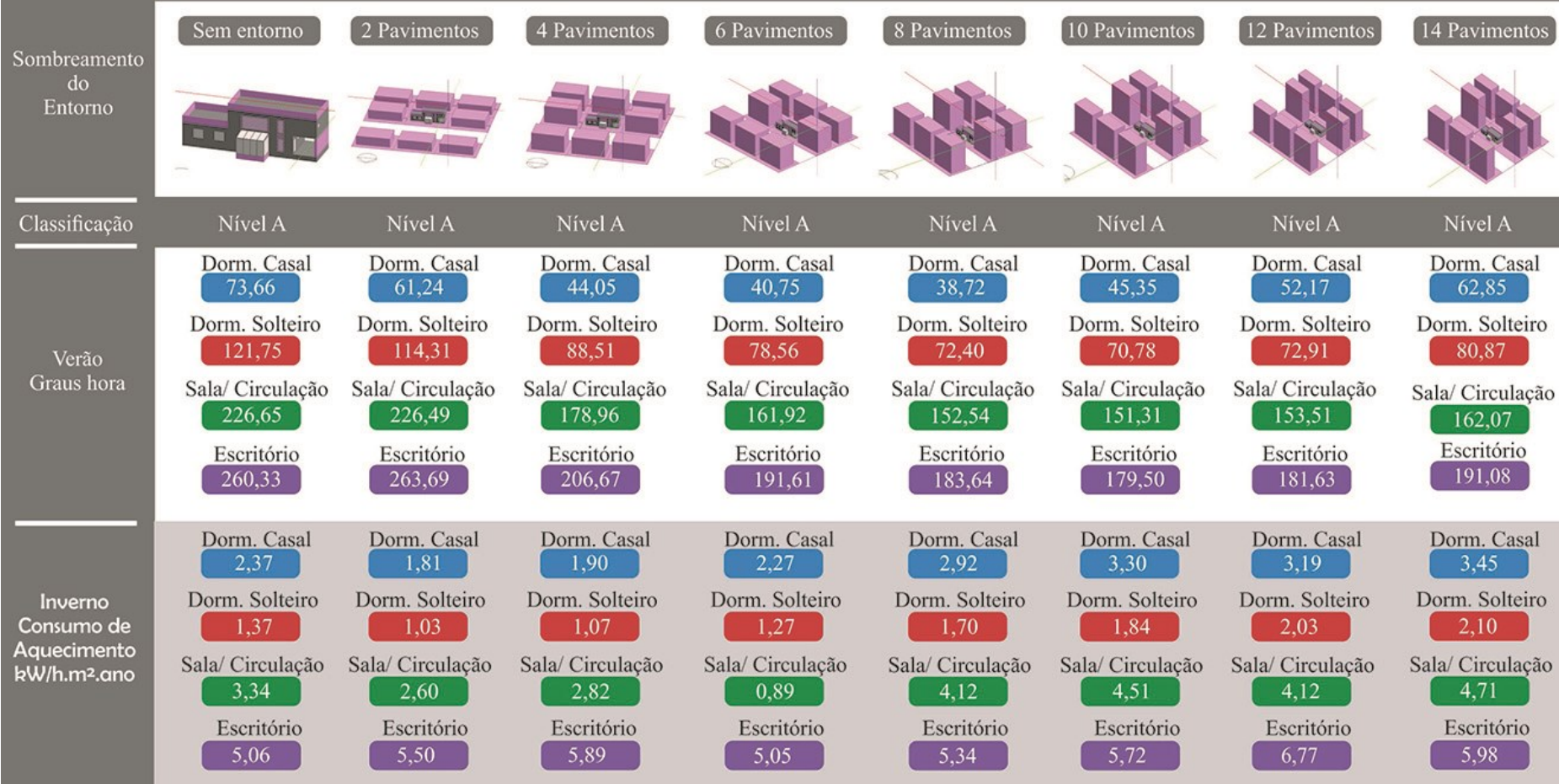

Fonte: Autores

Figura 10 - Classificação do nível de consumo energético com o uso de ar condicionado 24 horas

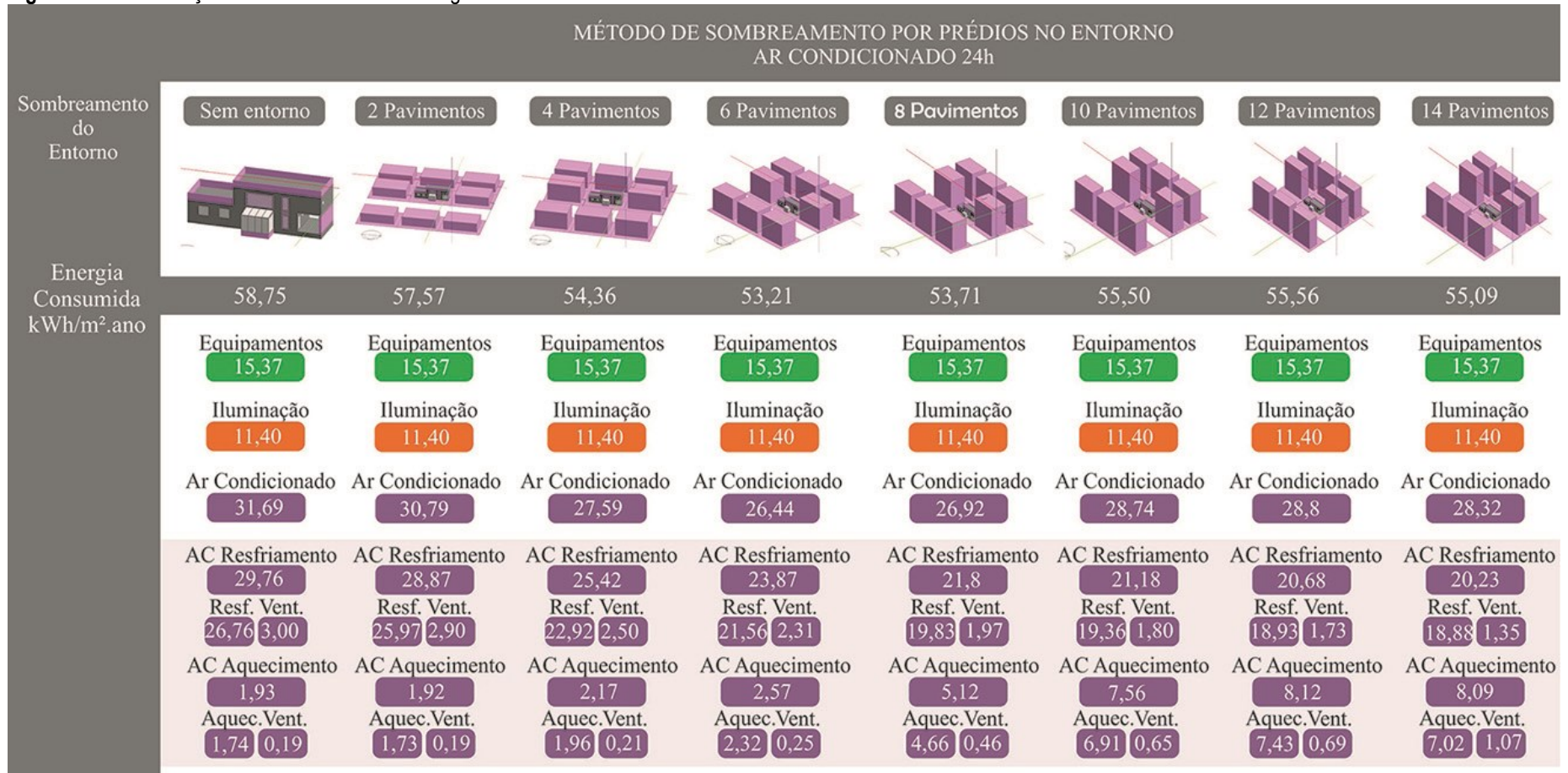

Fonte: Autores 
Figura 11- Fluxo Térmico para envoltória de inverno para ar condicionado 24 horas Entorno de 4 pavimentos - Inverno

Gráfico: Dormitórios

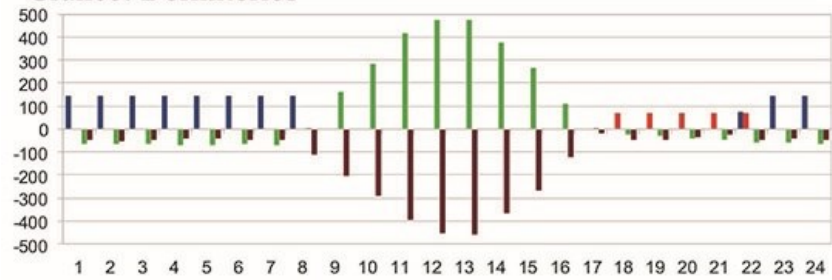

Entorno de 8 pavimentos

Gráfico: Dormitórios

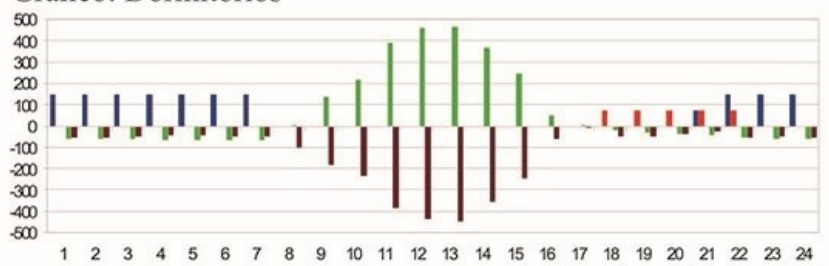

Condução - Superfícies Opacas (W) $\square$ Esquadrias (W) $\square$ Equipamentos (W)

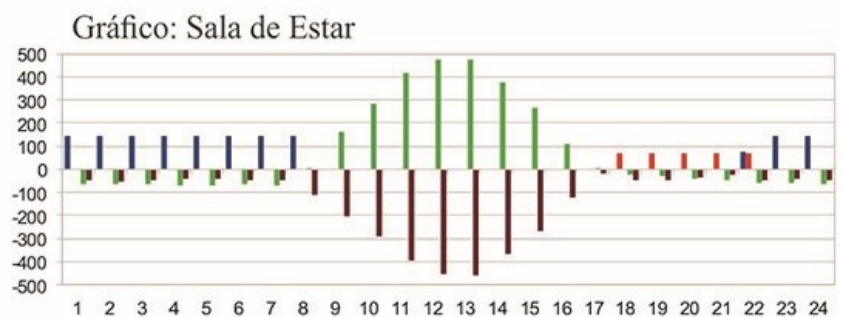

Gráfico: Sala de Estar

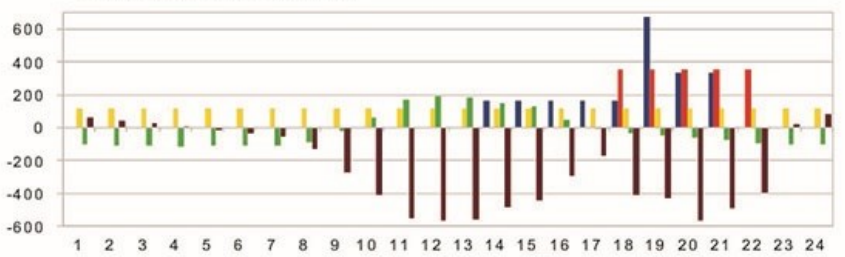

Iluminação (W)

Pessoas (W)

Fonte: Autores

Figura 12 - Fluxo Térmico para envoltória de verão para ar condicionado 24 horas

Entorno de 4 pavimentos - Verão

Gráfico: Dormitórios

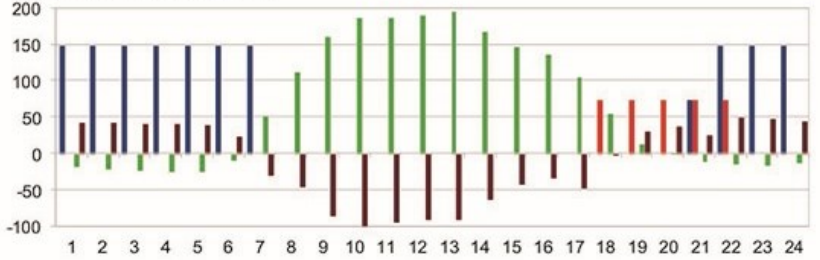

Entorno de 8 pavimentos - Verão

Gráfico: Dormitórios

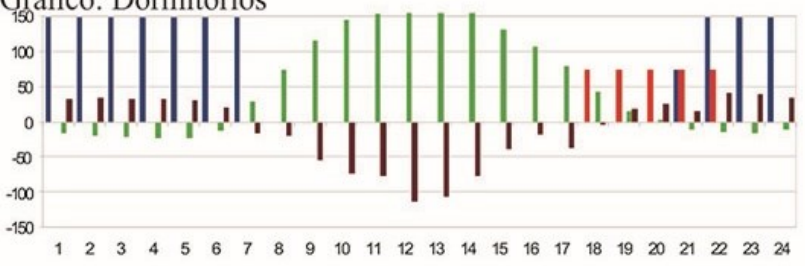

Condução - Superfícies Opacas (W) $\square$ Esquadrias (W)
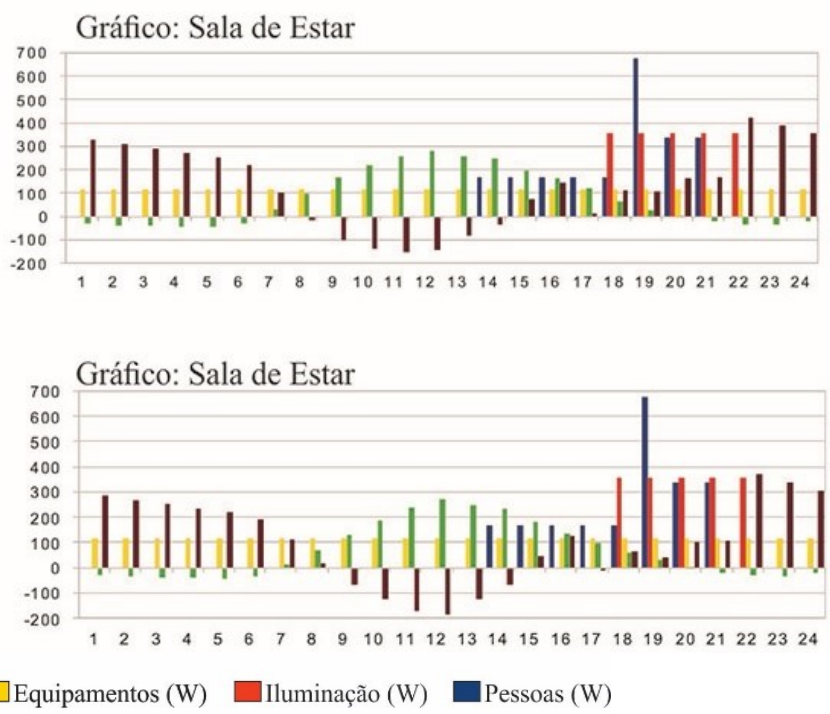

Fonte: Autores

entorno de 8 pavimentos obteve um consumo maior em $17,7 \%$ do que a configuração com entorno de 4 pavimentos, no período das $9 \mathrm{~h}$ às $14 \mathrm{~h}$, com pico as $12 \mathrm{~h}$.

\section{Edifício ventilado naturalmente 24 horas}

$\mathrm{Na}$ edificação ventilada naturalmente 24 horas por dia, a situação com entorno de 6 pavimentos apresentou o maior índice de conforto térmico, com $97,72 \%$, conforme Figura 13 , enquanto que as configurações que apresentaram os menores foram os de 10 e 12 pavimentos com 92,15\%, conforme apresenta a Figura 13. Assim, para o inverno e verão, percebeu-se que o ganho de calor ficou muito próximo, pois em ambos os casos as configurações com entorno de 4 pavimentos, receberam aproximadamente
$2,0 \%$ a mais de calor proveniente da radiação solar direta do que a configuração com entorno de 8 pavimentos que apresenta maior grau de sombreamento e por sua vez, perdeu mais calor pelas paredes da sala de estar.

O exemplar com entorno de 4 pavimentos apresentou maior ganho de radiação solar do que os demais, e por isso possui maior soma de graus-hora por calor, pois a ventilação natural não consegue manter a temperatura do ar interno abaixo da temperatura do ar externo, causando um sobreaquecimento do interior da edificação. Enquanto que a configuração com entorno de 8 pavimentos, apresentou sombreamento completo no período das $9 \mathrm{~h}$ e $15 \mathrm{~h}$, no inverno, conforme o infográfico do rastreamento, 
Figura 13. Infográfico de conforto térmico

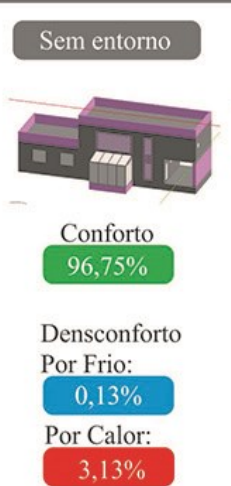

Fonte: Autores

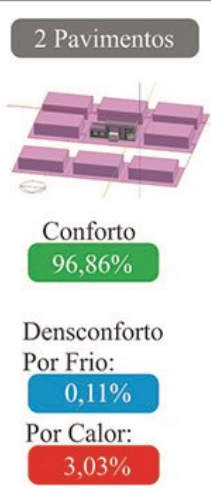

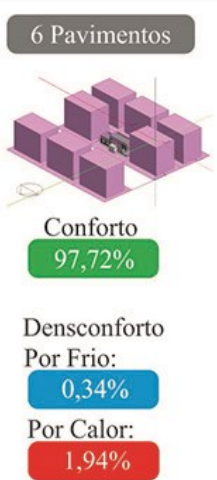

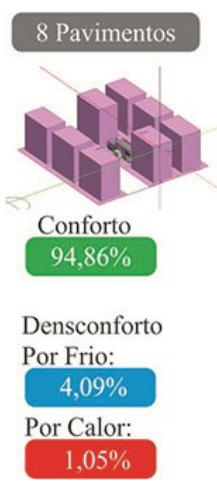

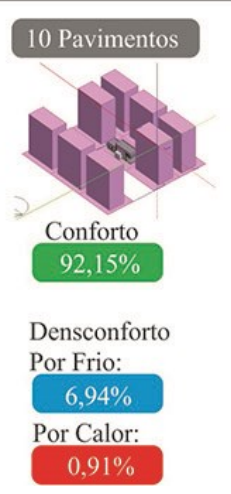

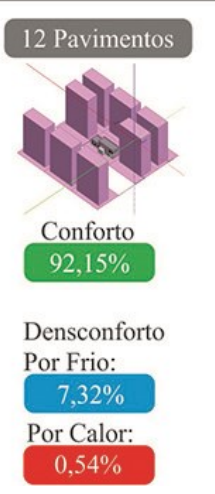

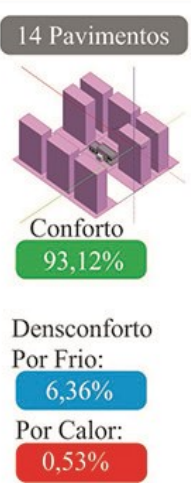

reduzindo a temperatura radiante das paredes externas e internas, aumentando, portanto, o número de graus-hora de aquecimento. A Quadro 8 sintetiza os resultados das simulações computacionais caracterizando a melhor condição de sombreamento da edificação (6 pavimentos) e as situações de entorno pouco densificado (2 pavimentos) e muito densificado (14 pavimentos).

Quadro 8 - Síntese do sombreamento da edificação residencial

\begin{tabular}{|c|c|c|c|}
\hline $\begin{array}{c}\text { Áreas } \\
\text { sombreadas }\end{array}$ & $\begin{array}{c}\text { Entorno de 2 } \\
\text { pavimentos }\end{array}$ & $\begin{array}{c}\text { Entorno de 6 } \\
\text { pavimentos }\end{array}$ & $\begin{array}{c}\text { Entorno de 14 } \\
\text { pavimentos }\end{array}$ \\
\hline $\begin{array}{c}\text { Janelas } \\
\text { sombreadas }\end{array}$ & Sim & Sim & Sim \\
\hline $\begin{array}{c}\text { Paredes } \\
\text { sombreadas }\end{array}$ & Não & Sim & Sim \\
\hline $\begin{array}{c}\text { Cobertura } \\
\text { sombreada }\end{array}$ & Não & Não & Sim \\
\hline $\begin{array}{c}\text { Consumo de } \\
\text { Climatização }\end{array}$ & $31,69 \mathrm{kWh} / \mathrm{ano}$ & $26,44 \mathrm{kWh} / \mathrm{ano}$ & $28,32 \mathrm{kWh} / \mathrm{ano}$ \\
\hline $\begin{array}{c}\text { Nível de } \\
\text { Conforto }\end{array}$ & $96,75 \%$ & $97,72 \%$ & $93,12 \%$ \\
\hline Térmico & & & \\
\hline
\end{tabular}

Fonte: Autores

\section{Conclusões}

Observou-se com o desenvolvimento da pesquisa, que o melhor desempenho termoenergético da edificação ocorreu quando a mesma esteve sombreada em um entorno de 6 pavimentos. Assim, constatou-se que durante o período de verão o sistema de proteção solar bloqueia a radiação solar direta no interior da edificação. No período de inverno, o entorno gera um sombreamento total do plano vertical, não afetando a cobertura, plano horizontal, no que diz respeito à radiação solar direta. $\mathrm{O}$ ganho térmico proporcionado pelo plano horizontal à edificação, somado aos ganhos internos provenientes do sistema de iluminação, da ocupação, e dos equipamentos, é suficiente para manter a temperatura interna em condições de conforto. Nos entornos de 2 e 4 pavimentos a radiação solar direta no plano vertical, nesse caso, opaco já que o transparente é protegido, gera um aumento da temperatura superficial das paredes, e consequente maiores ganhos térmicos. Quando a edificação esteve sombreada em entorno com 8, 10, 12 e 14 pavimentos, o sombreamento da cobertura, além das paredes, aumentou a necessidade energética de aquecimento da edificação. Embora em termos de percepção e conforto térmico dos espaços abertos a radiação solar direta seja extremamente relevante no período de inverno, principalmente, no caso de uma edificação com elevado nível de isolamento térmico, o maior sombreamento, desde que não atingindo a cobertura, gerou um melhor desempenho termoenergético do envelope. A discussão do sombreamento da cobertura e das paredes de edifícios residenciais com elevado nível de isolamento térmico preenche uma lacuna no âmbito do desempenho termoenergético de edificações residenciais, e conduz a novas discussões no âmbito das relações entre a configuração urbana e o desempenho termoenergético de residências unifamiliares em zonas bioclimáticas com estação fria.

\section{Limitações do trabalho}

A pesquisa apresenta algumas limitações que são caracterizadas na sequência e que nortearão o desenvolvimento de futuros trabalhos. A primeira limitação refere-se à abordagem qualitativa do rastreamento de sombras. Embora tenha sido possível observar e analisar o sombreamento das paredes e da cobertura na análise, um aprofundamento nessa abordagem possibilitará uma discussão melhor embasada. Uma segunda limitação do trabalho é referente às possibilidades de variação do entorno. A generalização das condições de contorno do entorno é possível, por outro lado depende dos planos diretores e códigos de obras das cidades a serem analisadas. 


\section{Referências}

ABNT - ASSOCIAÇÃO BRASILEIRA DE NORMAS TÉCNICAS. NBR 15.220: Norma Brasileira de Desempenho Térmico de Edificações. Rio de Janeiro, 2005.

ABNT - ASSOCIAÇÃO BRASILEIRA DE NORMAS TÉCNICAS. NBR 15.575: Edifícios Habitacionais - Desempenho. Rio de Janeiro, 2013.

ANSI/ASHRAE - AMERICAN NATIONAL STANDARD INSTITUTE / AMERICAN SOCIETY OF HEATING, REFRIGERATING AND AIR-CONDITIONING ENGINEERS. Standard 55: Thermal Environmental Conditions for Human Occupancy. Atlanta, 2010.

ASSIS. E. S. de. A abordagem do clima urbano e aplicações no planejamento da cidade: reflexões sobre uma trajetória. In: ENCONTRO NACIONAL DE CONFORTO DO AMBIENTE CONSTRUÍDO. 7., Maceió, 2005. Anais... Maceió: ANTAC, 2005.

CARVALHO, Homero et al. Relação entre o Sombreamento provocado pelas edificações e o Campo Térmico. In: ENCONTRO NACIONAL DE CONFORTO DO AMBIENTE CONSTRUÍDO. 9., Natal, 2009. Anais... Natal: ANTAC, 2009.

CHVATAL, Karin M. S., CORVACHO, Helena. The impact of increasing the building envelope insulation upon the risk of overheating in summer and an increased energy consumption. Journal of Building Performance Simulation. v. 2, n. 4, p. 267-282, dez. 2009. http://dx.doi.org/10.1080/19401490903095865

DALBEM, Renata ; FREITAS, J.R. ; CUNHA, Eduardo Grala da. Conceito Passivhaus Aplicado ao Clima Brasileiro. Revista de Arquitetura IMED, Passo Fundo, v. 4, p. 26-36, 2015. http://dx.doi.org/10.18256/2318-1109/arqimed.v4n1p26-36

DALBEM, Renata, et al. Discussão do desempenho da envoltória de uma passive house adaptada à zona bioclimática 2 em acordo com o RTQ-R. Ambiente Construído, v.17, no.1, p.201-222, Mar 2017. http://dx.doi.org/10.1590/s1678-86212017000100132

DÍAZ-VILARIÑO,, L; LAGÜELA, S.; ARMESTO, J.; ARIAS, P. Semantic as-built 3d models including shades for the evaluation of solar influence on buildings. Solar energy, v. 92, p. 269-279, 2013. http://dx.doi.org/10.1016/j.solener.2013.03.017

EPBD. Directive 2010/31/EU of the European Parliament and of the Council of 19 May 2010 on the energy performance of buildings. Official Journal, European Union Legislation, v. 53, n.153, p. 13-35, 2010.

INMETRO - INSTITUTO NACIONAL DE METROLOGIA, NORMALIZAÇÃO E QUALIDADE INDUSTRIAL. RTQ-C. Requisitos Técnicos da Qualidade para o Nível de Eficiência Energética de Edifícios Comerciais, de Serviços e Públicos. INMETRO, Rio de Janeiro, 2013.

INMETRO - INSTITUTO NACIONAL DE METROLOGIA, NORMALIZAÇÃO E QUALIDADE INDUSTRIAL. RTQ-R. Requisitos Técnicos da Qualidade para o Nível de Eficiência Energética de Edifícios Residenciais. INMETRO, Rio de Janeiro, 2012 .

JOHANSSON, E.; SPANGENBERG, J.; GOUVÊA, M. L.; FREITAS, E. D. Scale-integrated atmospheric simulations to assess thermal comfort in different urban tissues in the warm humid summer of São Paulo, Brazil. Urban Climate. v. 23, p. 24-43, 2013. http://dx.doi.org/10.1016/j.uclim.2013.08.003

MCLEOD, Rob., MEAD, Kym., STANDEN, Mark. Passivhaus primer: Designer's guide A guide for the design team and local authorities. 2016. Disponível em

http://www.passivhaus.org.uk/filelibrary/Primers/KN4430_Passivhaus_Designers_Guide_WEB.pdf. Acesso em: 10 de outubro de 2016.

MASCARÓ, Lúcia; MASCARÓ, Juan José. Ambiência Urbana. Porto Alegre: Masquatro, 2009.

MARTINS, D. J.; RAU, S. L.; RECKZIEGEL, S.; FERRUGEM, A. P.; SILVA, A. C. S. B. Ensaio sobre a Utilização da Automação de Aberturas na Simulação do Desempenho Térmico de Edificações. In: ENCONTRO NACIONAL DE CONFORTO NO AMBIENTE CONSTRUÍDO, 10. Anais... Natal, ENTAC, 2009.

MORENO, J. A. Clima do Rio Grande do Sul. Porto Alegre: Secretaria da Agricultura, 1961. 42 p. 
OLIVEIRA. Liader da Silva. Avaliação dos limites das propriedades térmicas dos fechamentos opacos da NBR 15220-3, para habitações de interesse social, da Zona Bioclimática 2. Dissertação (Mestrado em Arquitetura), Programa de Pós-Graduação em Arquitetura, Universidade Federal de Pelotas, Pelotas, 2015.

ORIOLI, A.; GANGI, A. DI. An improved photographic method to estimate the shading effect of obstructions. Solar energy, v. 86, n. 11, p. 3470-3488, 2012. http://dx.doi.org/10.1016/j.solener.2012.07.027

PACHECO, Miguel. Ventilação Natural e Climatização Artificial: Crítica ao modelo Super-isolado para residência de energia zero em Belém e Curitiba. Tese (Doutorado em Engenharia Civil). Universidade Federal de Santa Catarina, Florianópolis, 2013.

PEEL, M. C. and FINLAYSON, B. L. and MCMAHON, T. A. Updated world map of the Köppen-Geiger climate classification. Hydrology and Earth System Sciences. v.11. p. 1633-1644, mar. 2007. http://dx.doi.org/10.5194/hess-11-1633-2007

POUEY, Juliana Al-Alam. Projeto de edificação residencial unifamiliar para a zona bioclimática 2 com avaliação termo energética por simulação computacional. Dissertação (Mestrado em Arquitetura), Programa de Pós-Graduação em Arquitetura, Universidade Federal de Pelotas, Pelotas, 2011.

PASSIVE-ON PROJECT. A norma Passivhaus directrizes de projecto para casas confortáveis de baixo consumo energético, Parte I. Revisão de casas confortáveis de baixo consumo energético. Lisboa: INETI, 2007.

ROMERO, Marta. Correlação entre o microclima urbano e a configuração do espaço residencial de Brasília. Fórum Patrimônio. v. 4, n.1, 2011.

PREFEITURA MUNICIPAL DE PELOTAS, Lei número 1672, Plano Diretor de Pelotas. 2008.

SOARES, Maicon Motta. Avaliação dos parâmetros de desempenho térmico da NBR15575/2013: habitações de interesse social na zona bioclimática 2. Dissertação (Mestrado em Arquitetura), Programa de Pós-Graduação em Arquitetura, Universidade Federal de Pelotas, Pelotas, 2015.

\section{${ }^{1}$ Sílvia Ruzicki Pereira}

Acadêmica do Curso de Arquitetura e Urbanismo da Universidade Federal de Pelotas. Rua Benjamin Constant 1359, Centro, Pelotas, RS, Brasil, CEP:96010-020

${ }^{2}$ Carolina de Mesquita Duarte

Acadêmica do Curso de Arquitetura e Urbanismo da Universidade Federal de Pelotas. Rua Benjamin Constant 1359, Centro, Pelotas, RS, Brasil, CEP:96010-020

\section{${ }^{3}$ Eduardo Grala da Cunha}

Arquiteto. Doutor em Arquitetura. Rua Benjamin Constant 1359, Centro, Pelotas, RS, Brasil, CEP:96010-020

\section{${ }^{4}$ Lisandra Fachinello Krebs}

Arquiteta. Mestre em Arquitetura. Rua Benjamin Constant 1359, Centro, Pelotas, RS, Brasil, CEP: 96010-020

\section{${ }^{5}$ Rodrigo Karini Leitzke}

Acadêmico do Curso de Ciência da Computação da Universidade Federal de Pelotas. Rua Benjamin Constant 1359, Centro, Pelotas, RS, Brasil, CEP: 96010-020

\section{${ }^{6}$ Antonio César Silveira Baptista da Silva}

Arquiteto. Doutor em Engenharia Civil. Rua Benjamin Constant 1359, Centro, Pelotas, RS, Brasil, CEP: $96010-020$

\section{${ }^{7}$ Letiane Benincá}

Arquiteta. Mestre em Arquitetura. Rua Senador Pinheiro, 304, Passo Fundo, RS, Brasil, CEP: 99070-220 